\title{
SOBRE A INCOMPATIBILIDADE DAS AÇÕES DECLARATÓRIAS DE CONSTITUCIONALIDADE COM A NATUREZA DAS NORMAS JURÍDICAS
}

\author{
Guilherme de Negreiros Diógenes Reinaldo ${ }^{109}$
}

Recebido em: 06/12/2018

Aprovado em: 25/03/2019

\begin{abstract}
RESUMO
O objetivo deste artigo é debater se há com compatibilidade entre a natureza da legalidade e o instrumento de controle de constitucionalidade previsto no artigo 102, $\$ 2^{\circ}$ da Constituição Federal brasileira e disciplinado na Lei 9.868 de 1999, chamado "ação declaratória de constitucionalidade". A metodologia empregada foi a de análise de construções conceituais oriundas da filosofia analítica do Direito, especificamente as noções de "autoridade enquanto serviço" e "razões protegidas" defendidas por Joseph Raz, bem como a teoria do Direito como planos (planning theory of Law) sustentada por Scott J. Shapiro a partir do conceito de "circunstâncias da legalidade". Também é explicada qual a utilidade de aprofundar o debate sobre estes conceitos e as consequências do ponto de vista prático em aceitar tais perspectivas. Conclui-se que o referido instituto é incompatível, do ponto de vista conceitual, com a natureza das normas jurídicas.
\end{abstract}

Palavras-chave: Ação declaratória de constitucionalidade. Planejamento Social. Razões protegidas. Circunstâncias da legalidade.

\section{INTRODUÇÃO}

O objeto de estudo deste artigo é debater se há com compatibilidade entre a natureza da legalidade e o instrumento de controle de constitucionalidade previsto no artigo $102, \S 2^{\circ}$ da Constituição Federal brasileira e disciplinado na Lei 9.868 de 1999, chamado "ação declaratória de constitucionalidade".

$\mathrm{O}$ interesse pelo referido instrumento se dá em um contexto de proeminência do seu uso pela comunidade jurídica brasileira, sobretudo em razão da notoriedade de certas matérias que foram e serão discutidas pelo Supremo Tribunal Federal através do julgamento de ações declaratórias de constitucionalidade.

\footnotetext{
${ }^{109}$ Mestrando em Direito pela Universidade Federal do Rio Grande do Norte - UFRN.
} 
Apesar de sua utilização frequente, o problema de pesquisa que se coloca neste artigo é o de analisar a compatibilidade deste instituto com a natureza das normas jurídicas. Especificamente, parte-se da premissa básica de que estas últimas são presumidamente constitucionais, para construir a hipótese de que o referido instituto é incompatível com a lógica da legalidade.

Para tanto, primeiramente, serão feitos no tópico " 1 ", apontamentos sobre o que é a ação declaratória de constitucionalidade e uma análise sobre o tratamento dado pela dogmática jurídica ao tema.

Prosseguindo, a metodologia para investigação do problema a ser adotada é a de aprofundamento do debate sobre certos conceitos oriundos da Filosofia Analítica do Direito, com o objetivo de que possam ser extraídas conclusões úteis para a análise do problema apontado acima.

Especificamente, é abordado no tópico "2" o conceito de "razões protegidas" (subtópico 2.1) defendido por Joseph Raz em seu livro Razões Práticas e Normas, sua natureza preemptória e o papel que desempenhariam no balanço de razões de um agente racional.

Ainda analisando as ideias de Raz, são tecidas considerações sobre a concepção de autoridade legítima (subtópico 2.2) defendida por ele ${ }^{110}$, com o objetivo de trazer alguma luz sobre qual utilidade das leis e dos sistemas jurídicos para os indivíduos.

Esse debate se mostra extremamente relevante tanto do ponto de vista jurídico como político, em virtude de vivenciarmos no Brasil hodiernamente uma grave crise de representatividade que causa como consequência direta uma falta de identificação do cidadão de uma maneira geral, com as leis.

Posteriormente, no tópico " 3 ", o foco do estudo se volta sobre quais seriam, do ponto de vista antropológico e histórico, as condições sociais que fazem surgir o que Raz chama de autoridade legítima abordando esta questão através do conceito de circunstâncias da legalidade (subtópico 3.1), esboçado por Scott J. Shapiro, em seu livro Legality.

Debatendo-se, por último, sobre a natureza contraditoria da ação declaratória de constitucionalidade (subtópico 3.2).

Recorre-se ao estudo sobre tais conceitos, pois certos problemas de natureza social e jurídica podem assumir feições demasiadamente complexas, que não são capazes de ser explicadas simplesmente através da investigação nos moldes causa-consequência.

\footnotetext{
${ }^{110}$ Conceito introduzido em: RAZ, 1979; cujos principais elementos foram desenvolvidos em RAZ, 1986; e reformulados em RAZ, 2006.
} 
Mais do que isso, o debate, principalmente sobre as noções de autoridade enquanto serviço defendida por Raz e a concepção de Direito enquanto planos defendida por Shapiro, traz uma série de conclusões que podem ser aplicadas muito além do problema inicial apontado como objeto do artigo, uma vez que trata sobre a própria natureza dos institutos legais e qual o seu valor para as comunidades, e é por essa razão também que a leitura pode ser útil ainda que não haja um interesse do leitor pelo problema central abordado texto que é o da incompatibilidade das ações declaratórias de constitucionalidade com a natureza das normas jurídicas.

\section{CONSIDERAÇÕES SOBRE A AÇÃO DECLARATÓRIA DE CONSTITUCIONALIDADE}

A ação declaratória de constitucionalidade, como o próprio nome sugere, é um tipo de ação judicial cuja causa de pedir é que se declare judicialmente a constitucionalidade de determinada legislação ou ato normativo.

Está disciplinada nos artigos 102, §2 e 103 da Constituição Federal brasileira, e é, portanto, forma de controle de constitucionalidade concentrado, realizado pelo Supremo Tribunal Federal.

Em tese, qualquer dispositivo legal pode ser submetido à essa forma de controle de constitucionalidade, exigindo-se a demonstração objetiva da existência de controvérsia em torno da norma objeto da ação.

A ideia inicial de inseri-la na Constituição Federal surgiu no governo do presidente Fernando Collor, como uma tentativa do executivo de responder às frequentes alegações de inconstitucionalidade de certas leis e atos normativos editados à época, e que veio a encontrar certo apoio no Congresso Nacional, sob o argumento da necessidade se conferir maior segurança jurídica e vinculação à legalidade (ARAÚJO. 2011, p. 02/03).

Curiosamente, o Supremo Tribunal Federal, no julgamento da primeira ação declaratória de constitucionalidade, foi instado a se manifestar sobre a constitucionalidade do instrumento em si, reconhecendo-a, na ADC 1-1-DF, de relatoria do Ministro Moreira Alves em 01 de dezembro de 1993.

As controvérsias sobre o instituto geralmente giram em torno dos efeitos vinculantes que possui, e como isso supostamente pode violar o direito ao devido processo legal e à ampla defesa. Não será esta a objeção desenvolvida neste artigo. 
A argumentação que será esboçada se dá no sentido de que o instituto da ação declaratória de constitucionalidade é incongruente com a natureza da legalidade, para tanto, analisaremos o que o direito é, qual sua função, para a partir de então explicar a conclusão de que é conceitualmente contraditório que um sistema jurídico adote o referido instituto.

\section{DISCUSSÃO SOBRE OS CONCEITOS DE "RAZÕES PROTEGIDAS" E “AUTORIDADE ENQUANTO SERVIÇO” DEFENDIDOS POR JOSEPH RAZ}

Para analisarmos o que o direito é, do ponto de vista conceitual, partiremos do debate sobre certos conceitos oriundos da filosofia analítica do Direito, começando pelas noções de "razões protegidas" e "autoridade enquanto serviço" defendidos por Joseph Raz.

Neste momento, cabe a ressalva metodológica de que não se tem a pretensão, em nenhuma medida, de fazer uma análise sobre toda a discussão envolvendo a teoria das razões práticas ou as críticas que lhes são feitas, nem muito menos uma exposição integral das ideias defendidas por Joseph Raz sobre autoridade e moral.

Conforme o próprio Raz descreve sua pesquisa, o problema que trata é o da possibilidade de justificação racional da subsunção da vontade de um indivíduo sobre a de outro, e sobre a normatividade que autoriza que isso seja realizado (RAZ, 2006, p. 1003).

Nesse sentido, seria necessário muito mais do que um único artigo para debater a totalidade desses temas, algo que seria extremamente questionável do ponto de vista da relevância científica, principalmente quando se leva em consideração que há várias dissertações de mestrado e teses de doutorado dedicadas a rebater ou defender as ideias de Joseph Raz ${ }^{111}$.

O objetivo deste artigo é aprofundar o debate sobre certos conceitos da Filosofia Analítica do Direito e que servem como ferramentas para análise de um problema jurídico específico delineado nos tópicos anteriores.

Dessa forma, a análise sobre o conceito de "razões protegidas" e a concepção de autoridade enquanto serviço defendido por Joseph Raz é feita com a intenção de extrair conclusões úteis à tarefa proposta como objetivo.

3.1 Apontamentos sobre o conceito de "razões protegidas".

\footnotetext{
${ }^{111}$ Apenas para citar alguns, em defesa: CRAIG. 2009; e contrários: PERRY, 1989; ESSERT, 2011.
} 
Raz parte da premissa de que todo indivíduo que age racionalmente pauta sua conduta com base em um balanço de razões; isto é, diante de uma determinada situação, o indivíduo pondera as razões que ele teria para fazer ou não algo e a partir daí determina seu curso de ação.

Faz-se a ressalva que Raz descreve o que considera ser a forma de pensamento racional ideal, e que não considera que seja a mesma forma pela qual o raciocinador real se comporta na maioria das vezes, pois em muitos casos, o balanço de razões será influenciado por uma série de fatores estranhos ao pensamento racional. De todo modo, considera que esta é a forma pela qual se chega a conclusões com base exclusivamente na racionalidade.

Essa posição está em consonância com o pensamento de DEL VECCHIO (1979, p. 355), para quem “(...) a escolha das ações a praticar e a exclusão das outras que seriam fisicamente possíveis no lugar das escolhidas, efectua-se no campo subjetivo."

Se Raz está correto ou não ao fazer essa ponderação, como já ressaltado, não é um ponto que será abordado neste artigo. O motivo pelo qual se procede com esta construção conceitual é que ela é necessária do ponto de vista metodológico, como ficará claro mais adiante.

Segundo o Professor de Filosofia do Direito da Universidade de Oxford, essas razões podem ser divididas em três grupos. O primeiro deles, as razões de primeira ordem. Fazendo uma simplificação, seriam aquelas razões contingentes, isto é, aquelas razões que se tem para fazer ou não fazer algo.

Um indivíduo que fuma bastante ${ }^{112}$, por exemplo, teria razões de primeira ordem para fumar, que é o fato de que sente prazer ao fazer isso, e razões também de primeira ordem para não fumar, que são os danos à sua saúde, e em um determinado momento ele fará um balanço de razões e decidirá qual irá prevalecer.

Uma razão de segunda ordem, por outro lado, seria uma razão para agir ou deixar de agir com base em outra razão estabelecida. Por exemplo, caso o indivíduo faça uma promessa a um amigo de que irá parar de fumar, então ele criou uma razão de segunda ordem para não fazê-lo, que é a promessa que ele fez.

\footnotetext{
$112 \mathrm{O}$ exemplo do fumante é dado pelo Professor André Coelho na palestra "O positivismo jurídico depois de Dworkin" na II Jornada de Teoria do Direito: As Contribuições de Ronald Dworkin para o pensamento jurídico contemporâneo, em Belém, em setembro de 2013.
} 
No dia seguinte ao dia em que fez a promessa, ele não deixará simplesmente de sentir vontade de fumar, suas razões de primeira ordem permanecem, mas sua conduta está sendo pautada por uma razão de segunda ordem que se sobrepôs.

O que o indivíduo do exemplo fez ao realizar a promessa, foi abdicar daquelas razões de primeira ordem que previsivelmente se aplicariam ao caso, em prol de uma razão excludente ou de segunda ordem provocada pelo fato de ter prometido algo a alguém.

Detalhando a situação hipotética, caso num belo dia, posterior à promessa, ele fosse abordado por um excêntrico milionário no meio da rua, que lhe oferecesse um prêmio de um milhão de reais para que fumasse, estaria, nesta hipótese, livre para fumar, pois o que fez ao prometer algo a alguém, foi renunciar expressamente àquelas razões de primeira ordem que eram possíveis de prever quando foi feita a promessa. Logo, havendo uma razão de primeira ordem superveniente e suficientemente forte, o indivíduo estaria livre para ignorar as razões de segunda ordem.

Todavia, quando se está diante de razões excludentes que não cedem diante de nenhuma outra razão, tratam-se do que Raz chama de razões protegidas.

Para Raz, portanto, razões protegidas são razões que além de reivindicarem completamente a determinação da conduta em um determinado caminho, excluem todas as outras razões que se poderia ter para agir em contrário: "a systematic combination of a reason to perform the act required by the rule, and an exclusionary reason not to act for certain reasons (for or against that act)" (RAZ, 1990, p. 191).

Para descrever essa exclusão de outras razões que provoca a determinação da conduta é utilizado o termo preempção ${ }^{113}$.

Nesse sentido, para Raz, uma pessoa ou uma instituição possui autoridade desde que seja considerada pelos outros como possuindo autoridade, o que significa reconhecer que pelo menos algumas das ordens emanadas desta fonte seriam razões excludentes protegidas:

Either if he is regarded by others as having authority or if he should be so regarded. To regard a person as having authority is to regard at least some of his orders or other expressions of views as to what is to be done (e.g., his advice) as authoritative instructions, and therefore as exclusionary reasons. (RAZ, 1990, p.62).

Jean-Jacques Rousseau, já lecionava que "Ainda o mais poderoso de todos os homens não será suficientemente poderoso, se não souber converter o seu poder em direito e a obediência dos outros em dever." (ROUSSEAU, 2002, p. 14).

\footnotetext{
${ }^{113}$ A tese da preempção é esboçada em detalhes em RAZ, 1979, p. 27.
} 
Diante do exposto, apresenta-se como inevitável o seguinte questionamento: por qual motivo um indivíduo, ou um grupo de indivíduos abriria mão de suas próprias razões e liberdade de decisão para dar a outro ou outros a Autoridade necessária para emanar razões protegidas?

A resposta a essa pergunta será abordada no tópico seguinte, no qual se buscará também trazer alguma luz a um debate extremamente importante no meio jurídico e político brasileiro, que é sobre quais as condições necessárias para se considerar uma autoridade como legítima e o que isso implica do ponto de vista prático.

3.2 Considerações sobre a concepção de autoridade enquanto serviço.

Em síntese, a resposta dada por Raz ao questionamento posto no tópico anterior é a de que a pessoa ou grupo de pessoas a quem é atribuído autoridade estabelece um compromisso com seus subordinados, de que se forem respeitadas as razões protegidas emanadas dessa fonte normativa, se tornará mais fácil para toda a comunidade que sejam atingidos aqueles que são considerados seus objetivos.

Portanto, para que a autoridade seja considerada legítima ela precisa prestar uma espécie de serviço aos indivíduos que estão colocados sob suas razões protegidas, que é o de assegurar que a longo prazo, os interesses de todos serão garantidos ou pelo menos compatibilizados de maneira socialmente razoável dentro de um certo padrão de aceitabilidade:

\begin{abstract}
Raz's service conception of authority focuses on the special relation between reasons and action. Specifically, authorities are authorities insofar as they are providing protected reasons for action that meet the dependence, preemption, and normal justification thesis. The bottom line is that if someone is an authority, their directives, permissions, and their like offer special reasons for action that exclude one's personal consideration of one's first-order reasons for action. This does not mean that one cannot think about first-order reasons and judge them, but it does mean that one ought not to act on the excluded reasons. (CRAIG, 2009, p. 60.)
\end{abstract}

Aqui cabe ressaltar que todo ordenamento jurídico que existe ou já existiu reivindica sobre os indivíduos que o fato de ter indicado uma determinada conduta como correta é a que deve ser seguida. Mais do que isso, todos os sistemas jurídicos que já existiram, por mais injustos que tenham sido, reivindicam ter autoridade legítima, o que não significa em nenhuma medida que essa reivindicação seja verdadeira. 
Neste momento é oportuna a lição de Radbruch que "Todo poder é, em última análise, um poder sobre as almas. 'A única coisa que torna poderoso aquele que manda é a obediência daquele que obedece' —_ dizia Schiller" (RADBRUCH, 1979, p. 175).

Cabe a cada indivíduo decidir por si mesmo se determinada autoridade ao qual está submetido está lhe prestando um auxílio em alcançar aqueles que são seus interesses, ou se está apenas restringindo suas liberdades de forma arbitrária.

Verificada a segunda hipótese, o caminho a ser seguido pelo cidadão insatisfeito com as razões protegidas que lhes são impostas passa muito além do campo propriamente jurídico, isto por que a solução, via de regra, só pode ser encontrada no campo da atuação política concreta com o fim de alterar as próprias determinações do sistema vigente. ${ }^{114}$

\section{ANÁLISE SOBRE COMPREENSÃO DO DIREITO ENQUANTO PLANOS POR SCOTT J. SHAPIRO.}

Diante do que foi exposto, é importante deixar claro que a autoridade legítima conforme defendida por Joseph Raz não surge a partir de um contratualismo social fictício, mas sim a partir de fatos sociais específicos.

Assim, uma das formas de se explicar este fenômeno e a forma que será feita neste artigo é através da noção de circunstâncias da legalidade defendida por Scott J. Shapiro em seu livro Legality.

A razão pela qual se decide abordar o problema a partir dessa perspectiva se dá em virtude de que, além de ser extraído da Filosofia Analítica do Direito - assim como as noções de "razões protegidas" e de "autoridade enquanto serviço" defendida por Raz -, este conceito incorpora e expressa elementos inerentes à Antropologia, Sociologia e Psicologia Social, que serão úteis quando retornamos ao problema central das ações declaratórias de constitucionalidade.

\subsection{Considerações sobre o conceito de circunstâncias da legalidade.}

\footnotetext{
${ }^{114}$ Em verdade, "o conteúdo de uma ordem, se abstrairmos da sua imperatividade coativa, não pode exprimir-se senão por estas palavras: 'isto deve ser assim'. Ao sentido dum querer, desligado da sua base psicológica, é ao que chamamos de 'dever ser'; assim como ao conteúdo do respectivo imperativo, inteiramente desligado do processo psíquico do ato de mandar, é ao que chamamos uma norma” (RADBRUCH, op.cit. p. 170)
} 
Shapiro utiliza a expressão circunstâncias da legalidade para descrever aquelas condições sociais que demandam formas sofisticadas de planejamento social, e que são obtidas, do ponto de vista histórico e antropológico, sempre que uma determinada comunidade tiver problemas morais sérios e numerosos, cujas soluções são complexas, contenciosas, ou arbitrárias:

I am going to refer to the social conditions that render sophisticated forms of social planning desirable as the 'circumstances of legality'. The circumstances of legality obtain whenever a community has numerous and serious moral problems whose solutions are complex, contentious, or arbitrary. In such instances, the benefits of planning will be great, but so will the costs and risks associated with nonlegal forms of ordering behavior, such as improvisation, spontaneous ordering, private agreements, communal consensus, or personalized hierarchies. (SHAPIRO, 2011, p. 2363)

Segundo Shapiro, verificadas essas circunstâncias, os riscos associados a formas nãolegais de organização do comportamento, como improvisação, acordos privados, consenso comunitário e hierarquias personalizadas, são extremamente altos. Na mesma proporção em que se torna arriscado para essas comunidades recorrerem a métodos não-legais, os benefícios do planejamento social também serão altos.

Tais instituições para existir pressupõem em si um planejamento social compartilhado e dirigido aos membros de uma comunidade, sendo extremamente improvável que pudessem ser concretizadas apenas através de métodos não-legais.

Isto porque, alcançado certos patamares demográficos e de distribuição e especialização de tarefas, torna-se extremamente custoso e em muitos casos inviável, o engajamento comunitário para que seja feita uma nova deliberação social e prática sobre cada um dos problemas que surgem cotidianamente.

Pois qualquer comunidade que atinge tamanho considerável enfrenta ou já enfrentou problemas referentes à propriedade, obrigações contratuais, dever de zelo uns com os outros, níveis apropriados de impostos, limitações ao "poder público", legitimidade do uso da violência, apenas para citar algumas questões.

For it is plausible to suppose that any modestly sized community will face similar questions about ownership, contractual obligations, duties of care to one another, proper levels of taxation, limitations on public power, legitimacy of state coercion, and so on. Moreover, like the islanders, it will find that resorting exclusively to non legal forms of planning is an ineficient or inadequate way of resolving these questions. (SHAPIRO, 2011, p. 2360).

Nesse contexto, portanto, os indivíduos inseridos precisam recorrer a formas mais sofisticadas de organização institucional não só para solucionar os problemas que surgem, 
mas para fazê-los de uma forma eficiente em termos de custo de recursos e, sobretudo, de tempo.

Isso porque coordenar ações coletivas em escalas imensas como as necessárias nas sociedades contemporâneas, demandam a atuação conjunta de vários indivíduos que podem muitas vezes não compartilhar dos mesmos objetivos ou até mesmo possuírem concepções morais divergentes sobre o que deve ser feito.

Além da possibilidade de divergências morais entre os agentes sobre o que ser feito, há ainda a existência de indivíduos completamente indiferentes e alienados aos propósitos que podem ser adotados pela comunidade e que, apesar disso, precisam agir ou deixar de agir de determinada forma, para que certos objetivos sejam alcançados.

Instituições legais são capazes de responder a essa necessidade na medida em que pressupõem em si a noção de planejamento social em esferas autorizadas de discussão e produção de normas: "To settle the doubts and disagreements of its members in a costeffective manner, of even at all, requires sophisticated tecnhniques of social planning such as those provided by legal institutions.".

Nesse sentido, a principal contribuição que o conceito de circunstâncias da legalidade traz ao debate é o de reconhecer toda a necessidade que as sociedades contemporâneas têm por métodos e procedimentos sofisticados para guiar condutas e organizar a sociedade em torno de certos objetivos, e essa é uma premissa importante para que a partir daí possamos compreender o verdadeiro valor da legalidade.

A importância desse debate no Brasil se mostra cada vez mais proeminente em virtude, primeiramente, de uma notória deficiência de representatividade sentida pelo cidadão e o consequente sentimento generalizado de falta de identidade com as leis e atos legislativos produzidos pelas autoridades.

Estando a sociedade insatisfeita e não identificada com as leis que lhe governam, uma série de consequências advirão que vão desde o próprio desdém cotidiano com o conteúdo das normas, chegando até o fortalecimento de movimentos que exigem a distorção ou não aplicação da normatividade em certas circunstâncias ou em face de certos grupos de indivíduos ou até mesmo de uma maneira geral. Nesse contexto, a ação declaratória de constitucionalidade se manifesta como uma expressão dessa desconfiança com as fontes autorizadas de produção de norma.

Assim, trazer à consideração a noção de circunstâncias da legalidade serve justamente para relembrar as razões pelas quais existem instituições legais e qual o valor da lei para as sociedades contemporâneas. 
Isso porque, conforme Shapiro, o objetivo das leis é compensar as deficiências associadas às formas não legais de planejamento social, planejando da forma considerada ideal e adequada para a comunidade que lhe adota, ou seja, aplicando planejamentos socialmente sensíveis de uma maneira considerada socialmente aceitável.

Portanto, em compasso com esse ponto de vista, percebe-se que o Direito na verdade é constituído por planos ou planejamentos, criados por fatos sociais provocados pelas circunstâncias da legalidade:

\begin{abstract}
According to what I will call the "Planning Theory of Law" legal systems are institutions of social planning and their fundamental aim is to compensate for the deficiencies of alternative forms of planning in the circumstances of legality. Legal institutions are supposed to enable communities to overcome the complexity, contentiousness, and arbitrariness of communial life by resolving those social problems that cannot be solved, or solved as well, by nonlegal means alone. (SHAPIRO, 2011, p. 2373)
\end{abstract}

Diante disto, vale ressaltar que os planos possuem uma função, que é pôr fim a uma deliberação moral, política e pragmática sobre determinado assunto. Um plano é fixado - ou pelo menos deveria ser fixado se você toma como parâmetro a noção de autoridade enquanto serviço explicada anteriormente — quando analisadas as hipóteses possíveis, chega-se à conclusão, dentro das esferas autorizadas de produção de planejamentos, que o caminho a ser adotado é uma determinada hipótese.

Por exemplo, a norma contida no artigo 312 do Código de Processo Penal estabelece o planejamento de que as prisões no curso do processo ocorrerão nas hipóteses de garantia da ordem pública ou econômica, por conveniência da instrução criminal, ou para assegurar a aplicação da lei penal, desde que haja prova do crime e indício suficiente de autoria.

O que essa norma quer dizer, do ponto de vista do Direito como planos, é que houve em um determinado momento uma deliberação no âmbito das esferas autorizadas de criação de leis (Congresso Nacional e Gabinete da Presidência da República), e se chegou à conclusão, certa ou errada, de que a prisão processual seria em todos os casos, restrita às possibilidades indicadas pelo referido artigo.

Portanto, quando o intérprete estiver diante do instante de aplicação da normatividade, não é pertinente que ele faça novo debate sobre se as circunstâncias sociais e políticas escolhidas justificam o dever-poder ${ }^{115}$ do Estado de restringir a liberdade, ou se o ato

\footnotetext{
${ }^{115}$ A expressão dever-poder está na concepção de que a persecução criminal se cuida “(...) menos de um direito de punir e mais de um dever-poder de punir. Isso porque, na visão moderna decorrente de um sistema criminal pautado de acordo com o entendimento de que a teoria do processo penal tem raiz nos direitos fundamentais, o jus persequendi é oriundo da perspectiva objetiva dessa classe de direitos." (SILVA JÚNIOR, 2014. p. 1.565)
} 
realmente contribui para a correção do indivíduo, mas, tão somente, verificar se os requisitos estabelecidos pelo planejamento prévio estão preenchidos.

Quando um indivíduo ou uma comunidade adota um plano, coloca-se sob a governança de uma norma, de modo que esse poder de autocontrole é conferido pelos princípios da racionalidade instrumental e é essa capacidade que explica a eficácia do planejamento:

Planning psychology is unique not only because it enables planners to form mental states that control future conduct but insofar as it enables them to recognize that the formation of these states generates rational pressure to act accordingly. Thus, when a individual adopts a self-governing plan, the disposition to follow through is not akin to a brute reflex, it is instead mediated by the recognition that the plan is a justified standard of conduct and imposes a rational requirement to carry it out. (SHAPIRO, 2011, p. 1773)

Planos, portanto, são entidades ao mesmo tempo ideais e reais na medida em que são criados através da adoção e sustentados através da aceitabilidade de suas razões pelos indivíduos que estão submetidos a ele.

Por causa da hierarquia, impessoalidade e natureza compartilhada das instituições legais, sistemas jurídicos são duráveis, bem como capazes de reduzir drasticamente os custos associados a solucionar certos problemas sociais de forma eficiente.

E é esse verdadeiramente o valor das leis, é exatamente por isso que a consideramos ser valiosa e por isso que praticamente nenhuma teoria política ignora o Direito enquanto instituição social indispensável para o mundo como conhecemos.

Afinal, ubi homo, ibi societas; ubi societas, ibi jus.

A questão, todavia, é que o Direito é justamente uma estratégia para que se evite este problema. Como afirma o professor André Coelho ${ }^{116}$, o Direito é uma estratégia para nós não termos um debate sobre nossas razões contingentes "caso por caso". O Direito é uma estratégia para termos uma deliberação prática prévia que põe fim sobre qual a conduta correta a ser adotada em determinados casos, e que deve ser seguida como se segue um plano.

Portanto, levando em consideração que na concepção de Shapiro planos são entidades propositivas abstratas que exigem, permitem ou autorizam agentes para agir ou não agir em certas situações, e levando em consideração também que normas são entidades abstratas cuja função é a de guiar condutas e funcionar como um padrão para correção, temos a inevitável conclusão de que normas são planos ou planejamentos.

\footnotetext{
${ }^{116}$ Afirmação feita pelo professor André Coelho na palestra "O positivismo jurídico depois de Dworkin" na II Jornada de Teoria do Direito: As Contribuições de Ronald Dworkin para o pensamento jurídico contemporâneo, em Belém, em setembro de 2013.
} 
4.2 Sobre a natureza contraditória da ação declaratória de constitucionalidade.

Conforme delineado no tópico anterior, aceitar a teoria do Direito enquanto planos defendida por Shapiro implica em reconhecer que planos são um tipo de normas que são criados através de procedimentos autorizados e reconhecidos pela comunidade ou pelo menos pelos agentes estatais encarregados de aplicá-los, e cuja função é guiar a conduta dos indivíduos, na medida em que encerra, ou busca encerrar, o debate e os questionamentos sobre qual o caminho correto a ser seguido do ponto de vista dos valores sociais vigentes.

Neste sentido, esses planos, para que possuam autoridade legítima, precisam facilitar os indivíduos a atingirem aqueles que são seus interesses gerais, e por essa razão, percebe-se empiricamente que instituições legais são estruturadas a partir de planos que devem e podem ser compartilhados pela comunidade, mas que são direcionados primordialmente aos agentes encarregados de aplicar a lei.

Agora que está claro o que é o direito e sua utilidade para as comunidades, fica fácil de entender o motivo pelo qual o instituto da ação declaratória de constitucionalidade é incompatível com o sistema jurídico brasileiro ou qualquer outro sistema jurídico.

Porque, como já ressaltado, do ponto de vista conceitual, os atos normativos são produzidos quando analisadas todas as hipóteses, determina-se um caminho como o correto a ser seguido, levando em consideração que sua função é a de auxiliar os indivíduos a alcançar aqueles que são seus interesses gerais, e por essa razão são presumidamente constitucionais.

Desta forma, o instituto em análise é conceitualmente contraditório, pois existe para declarar a constitucionalidade de algo cuja constitucionalidade já está declarada, a partir do momento em que passa pelas esferas autorizadas de produção de normas.

Não se sustenta que todos os atos normativos são inquestionavelmente constitucionais. A tese esboçada neste artigo é a de que o único instrumento conceitualmente compatível com é a ação direta de inconstitucionalidade, pois, por via inversa, é ação judicial destinada a verificar a inconstitucionalidade de ato normativo, não ferindo, portanto, a lógica da legalidade.

Neste sentido, além de incompatível com a legalidade, a ação declaratória de constitucionalidade não possui nenhuma justificativa pragmática.

Melhor explicando, ambas ações são de competência do mesmo órgão julgador, que é Supremo Tribunal Federal, possuem os mesmos legitimados ativos, que são aqueles descritos 
no art. 103 da Constituição, e possuem o mesmo objetivo, que é o de realizar o controle de constitucionalidade abstrato de leis e atos normativos.

A única diferença, como se denota, é o pedido esboçado na petição, na medida em que uma pugna a declaração de inconstitucionalidade e a outra a declaração de constitucionalidade, contudo, o efeito destes atos é o mesmo: o reconhecimento de uma norma como constitucional ou não.

Ante o exposto, as esferas autorizadas de produção de normas (Congresso Nacional e Gabinete da Presidência da República) poderiam extinguir através de ato legislativo competente o instrumento da ação declaratória de constitucionalidade sem qualquer prejuízo para os cidadãos ou para o controle de constitucionalidade abstrato, uma vez que, além de incompatível com a lógica da legalidade, não possui uma utilidade específica que já não esteja satisfeita por algum outro instrumento legal.

\section{CONSIDERAÇÕES FINAIS}

Foi tomado como objetivo central do artigo discutir o problema sobre a natureza contraditória da ação declaratória de constitucionalidade, instituto destinado ao controle de constitucionalidade e regulado nos artigos $102, \S 2^{\circ}$ e 103 da Constituição Federal.

A estratégia metodológica utilizada foi a recorrer a certos conceitos oriundos da filosofia analítica do direito, cujo ponto de partida foi a concepção de "razões protegidas", defendida por Josepeh Raz, para quem existem certas razões que são preemptórias, isto é, reinvidicam a determinação completa da conduta dos indivíduos, por mais que eles discordem ou tenham outras razões para se comportar de determinada forma.

Essas razões, todavia, segundo Raz, só devem ser aceitas quando emanados de uma fonte de autoridade legítima, requisito de legitimidade que estaria preenchido desde que aquele que reinvidica autoridade preste uma espécie de serviço aos indivíduos, que é o de assegurar que no longo prazo, caso aquelas razões protegidas sejam cumpridas, será mais fácil para a comunidade e os indivíduos, que sejam alcançados aqueles que são considerados seus interesses gerais.

Ademais, essa autoridade legítima não surge a partir de um contratualismo social fictício, mas sim em decorrência de certos fatos sociais específicos, verificados quando uma comunidade está diante das circunstâncias da legalidade. 
Essa associação de ideias se coaduna com a concepção de Direito como planos ou planejamentos esboçada pelo Professor de Filosofia do Direito da Universidade de Yale, Scott J. Shapiro.

Foi debatido que a função dos planos é pôr fim à deliberação moral, política e pragmática sobre determinado assunto. Um plano é fixado — ou pelo menos deveria ser fixado se você toma como parâmetro a noção de autoridade enquanto serviço - quando, analisadas todas as hipóteses possíveis, chega-se à conclusão, dentro das esferas autorizadas de produção de planejamentos, sobre qual o caminho a ser adotado.

Diante dessas considerações, nos países em que se adota o constitucionalismo, $a$ Constituição é o plano mestre do ordenamento jurídico, pois não só estabelece os procedimentos válidos para criação e aplicação dos planejamentos sociais, como possui, em função da sua posição hierárquica, a força normativa suficiente para vincular todos os atos estatais de um Estado, e consequentemente vários aspectos da vida dos indivíduos, fornecendo como resultado uma forma eficiente de guiar e coordenar condutas e o comportamento em sociedade.

Esse debate tornou mais claro entender a natureza contraditória da ação declaratória de constitucionalidade, na medida em que a lei, por sua própria natureza, já pressupõe necessariamente uma prestação de serviço àqueles que estão subordinados à ela, que é o planejamento social destinado a assegurar que se torne mais fácil a todos que alcancem aqueles que são seus interesses gerais.

Por fim, defendeu-se ainda a inexistência de qualquer justificativa pragmática para a existência da ação declaratória de constitucionalidade, na medida em que possui os mesmos legitimados ativos, o mesmo órgão competente para julgamento, e o mesmo efeito que a ação direta de inconstitucionalidade.

Conclui-se que o caminho conceitualmente apropriado para analisar a constitucionalidade de uma norma é a ação direta de inconstitucionalidade, na medida em que seu papel é detectar o que deve ser uma anomalia, não ferindo, portanto, a lógica da legalidade.

Explicando-se, ao final, que eventual extinção, por parte das esferas autorizadas de edição de normas, da ação declaratória de constitucionalidade, não traria consequências negativas aos cidadãos e ao controle abstrato de constitucionalidade, em razão, justamente, da ausência de alguma funcionalidade específica que já não esteja abarcada por algum outro instrumento legal. 


\section{REFERÊNCIAS}

ARAÚJO, Arivaldo Fernandes de. A Ação Declaratória de Constitucionalidade e a interpretação tópica do direito. 2011. Disponível em: $<$ http://egov.ufsc.br/portal/conteudo/a\%C3\%A7\%C3\%A3o-declarat $\% \mathrm{C} 3 \%$ B3ria-deconstitucionalidade-e-interpreta $\% \mathrm{C} 3 \% \mathrm{~A} 7 \% \mathrm{C} 3 \% \mathrm{~A} 3 \mathrm{o}-\mathrm{t} \% \mathrm{C} 3 \% \mathrm{~B} 3$ pica-do-direito $>$.

CRAIG, Jason Thomas. Raz and His Critics: A Defense of Razian Authority. 2009. 71 f. Dissertação (Mestrado) - Curso de Filosofia, Georgia State University, Atlanta, 2009.

DEL VECCHIO, Giorgio. Lições de filosofia do direito. Trad. António José Brandão. Coimbra: Arménio Amado, 1979. p. 644.

ESSERT, Christopher. A Dilemma for Protected Reasons. Law And Philosophy 49 (2012), Ontario, v. 49, p.01-37, jul. 2011.

LUHMANN, Niklas \& De GEORGI, Raffaele. La sociedad de la sociedad. México: Herder, 2007.

PERRY, Stephen R.. Second-Order Reasons, Uncertainty and Legal Theory. 1989. 83 f. Dissertação (Mestrado) - Curso de Direito, University Of Pennsylvania Law School, Philadelphia, 1989;

RADBRUCH, Gustav. Tradução L. Cabral de Moncada. Filosofia do direito 6. ed. Coimbra: Arménio Amado, 1979.

RAZ, Joseph. Practical Reason and Norms. 2. ed. Nova Iorque: Oxford University Press, 1990.

RAZ, Joseph. The Authority of Law. Nova Iorque: Oxford University Press, 1979;

RAZ, Joseph. The Morality of Freedom. Nova Iorque: Oxford University Press, 1986.

RAZ, Joseph. Revisiting the Service Conception. Minnesota Law Review, Minneapolis, v. 90, p.1003-1044, 2006.

ROUSSEAU, Jean-Jacques. Do Contrato Social. Editora Ridendo Castigat Mores, 2002. 
SHAPIRO, Scott J.. Legality. Cambridge: Harvard University Press, 2011. Edição Kindle.

\title{
ABOUT THE INCOMPATIBILITY BETWEEN THE NATURE OF LEGALITY AND THE CONSTITUTIONALITY DECLARATORY ACTION
}

\begin{abstract}
The aim of this paper is to debate if there's any compatibility between the nature of legality and the constitutionality control instrument, present in the article $102, \S 2^{\circ}$ of the Brazilian constitution, called "constitutionality declaratory action". The methodology used was the analysis on the discussion of conceptual constructions from analytical jurisprudence philosophy; specifically, the notions of "service conception of authority" and "protected reasons", defended by Joseph Raz, as well as Scott J. Shapiro's planning theory of Law, taking as a starting point the concept of "circumstances of legality". Beyond that, it's also explained the utility and the consequences from a practical point of view of accepting such perspectives. Concludes that the referred institute is incompatible, from a conceptual point of view, with the nature of law.
\end{abstract}

Keywords: Constitutionality Declaratory Action. Social Planning. Protected Reasons. Circunstances of legality. 